\title{
MADM Approach for Optimization of Multiple Responses in EDM of En-353 Steel
}

\author{
Dinesh Kumar Kasdekar ${ }^{1}$ and Vishal Parashar $^{2}$ \\ ${ }^{1,2}$ Department of Mechanical Engineering \\ ${ }^{1}$ Madhav Institute of Technology \& Science, Gwalior-474005, India (M.P) \\ ${ }^{2}$ Maulana Azad National Institute of Technology, Bhopal-462051, India (M.P) \\ Corresponding Author Email.ID-dkasdekar82@gmail.com
}

\begin{abstract}
Experiments is conducted on a die-sinking electric discharge machine under different conditions of process parameters. The experiment is carried out by using En-353 grade stainless steel as a work material and a copper as a tool electrode in EDM. This study highlights the application of technique for order preference by similarity to an ideal solution. In this (TOPSIS), simple additive weighting (SAW) based MCDM methods is used and conducts a study through computational experiments. Comprehensive discussions have been made on the influence of weight constraints and score functions. Where the score function represents an aggregated effect of positive and negative evaluations in performance ratings closeness to the ideal solution. The model developed in this study can be used as a systematic framework for process parameter optimization in conscious manufacturing process.
\end{abstract}

Keywords: Performance parameter, EDM, Entropy, TOPSIS, SAW

\section{Introduction}

Die sinking Electrical Discharge Machining (EDM) is one of the most popular nontraditional manufacturing process suitable for machining of very hard and brittle materials. The machining process are non-conventional in this sense that they do not employ traditional tools for metal removal but they directly use other forms of energy. The problems of high complexity in size, shape and higher demand for product accuracy and surface finish can be solved through non-traditional methods. Recent advances in the EDM technology made it a valuable and viable process in the manufacturing of critical parts such as medical, sports, surgical, optical, instruments, aerospace and aeronautical components including automotive R\&D areas. EDM has been established to applicable in machine and electrically conductive materials such as stainless steels, tool steel, carbides, super alloys, ceramic etc. In spite of their other physical and metallurgical properties [1]. The quality of the machined parts in EDM is significantly affected by control parameters [2]. Optimal machining conditions are accomplished by executing a detailed analysis of all the factors affecting the process and also the interactions between them. The major factors influencing EDM process are Pulse on time, Pulse off time, Spark gap, Gap current, etc. and physical properties of electrode, work piece and dielectric fluid [3]. As a well-known classical MCDA/MCDM method, MCDM methods has been used which is quite effectively in industrial applications to optimize and solve real-world decision problems [4-7]. Methods such as the Technique for Order Preference by Similarity to Ideal Solution (TOPSIS), Simple Additive Weighting (SAW) or weighted sum model (WSM), Weighted Product Method (WPM) are widely used methods. However, these methods have their own advantages and disadvantages [4]. Previous MADM methods presented by researchers there is a limited number of studies have been conducted in terms of graphical method and no method has been presented based on the proposed 
algorithm. Among many MADM methods available in research, we have chosen TOPSIS, SAW and WPM. The rational for selection is that most of these methods are among the more popular and widely used methods $[4,5,8]$. SAW and WPM assume additive and multiplicative weighted preferences in an interval scale [9]; and SAW is selected its simplicity which makes it often used by practitioners. Even some researchers argue that SAW should be the standard for comparisons. The researchers found that in $40 \%$ of cases, each method presents a result, which is different from the other one [10]. The objective of the present work is to study the characteristic features of the EDM process as reflected through Taguchi design based experimental studies with various process parametric combinations like discharge current, Pulse on Time (POT), Pulse off Time (POF) \& dielectric fluid on Material removal Rate (MRR), tool wear rate \& Surface Roughness (Ra). Initially nine experimental runs are conducted where the significant process parameters are identified. The objective being conflicting in nature, it is very difficult to achieve them simultaneously by a single set of process variables [11]. In the present work, MCDA/MCDM technique is attempted to establish a set of process variables that yields high MRR but simultaneously keeps the tool wear rate and Surface roughness $(\mathrm{Ra})$ reasonably low [12]. In order to achieve this, nine experimental runs are performed, simultaneous optimization of the responses. The result analysis is carried out by statistical software MINITAB, version 16. This paper mainly focuses the different multiple criteria decision making (MCDM) methods such as TOPSIS, Simple Additive Weighting (SAW), for selection of alternative. Both the methods are based on an aggregating function that represents closeness to the ideal solution. However, very few researchers have attempted to optimize the machining parameters using multi-responses simultaneously using Entropy-TOPSIS, SAM. In this study Entropy-TOPSIS, SAM is applied for simultaneous optimization of three important performance measures of the Electric discharge machine.

\section{Preliminaries}

In this section, basic definitions of Entropy-TOPSIS, SAW, and WPM are presented. Nowadays, multi-criteria (or attribute) decision making (MCDM/ MADM) methods are more widely used in practice. These methods are based on logical decision-making approaches and have a higher potential to solve decision-making problems in manufacturing environments (Rao, 2007). A schematic block diagram describing the methodology adopted in this paper has been shown in Figure 1.

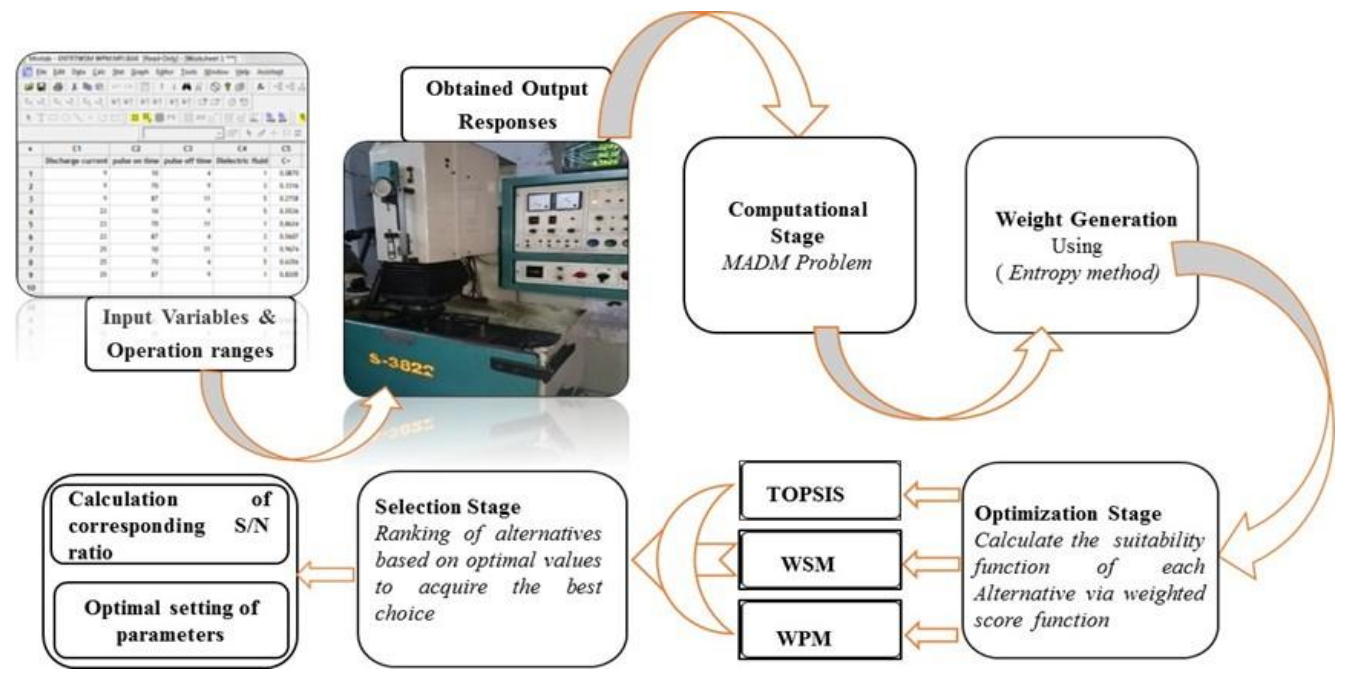

Figure 1. Schematic Block Diagram for Entropy based TOPSIS, SAM Methodology 


\subsection{Entropy Approach for Weights Determination}

Entropy method is one of the well-known and widely used methods to calculate the criteria of decision weights. Decision weights increases the importance of criteria and is usually categorized into two types. One is subjective weight which is determined by the knowledge and experience of experts or individuals, and the other is objective weight which is determined mathematically by analyzing the collected data. Here, it is an objective weighting method. In TOPSIS, determine the weights of each quality characteristics [13]. Discrete type of entropy is used in TOPSIS entropy measurement for properly conduct weighting analysis. Entropy method is used for calculating weights which is determined by following steps, [14]:

Step 1: Determine the decision matrix.

This step includes the progress of matrix arrangement. The row of the matrix is assigned to single alternative and every column to single characteristic. The normalized decision making matrix can be showed as:

$$
\check{\mathrm{D}}=\begin{gathered}
A_{1} \\
A_{\mathrm{i}} \\
A_{m}
\end{gathered}\left[\begin{array}{llllc}
y_{11} & y_{12} & \cdot & y_{1 j} & y_{1 n} \\
y_{i 1} & y_{i 2} & \cdot & y_{i j} & \cdot \\
y_{m 1} & y_{m 2} & \cdot & y_{m j} & y_{m n}
\end{array}\right]
$$

Here, $A_{i}(i=1,2,3 \ldots m)$ signifies the potential substitutes; $y_{i}(j=1,2,3, \ldots n)$ signifies the attributes associated to another performance, $j=1,2,3, \ldots n$, and $y_{i j}$ is the performance of $A_{i}$ with respect to characteristic $\mathbf{y}_{\mathfrak{i}}$.

Step 2: Formation of Normalized Decision Matrix $\left(\bar{Y}_{\mathrm{ij}}\right)$

In matrix $\check{D}, Y_{i j}$ is of the $i^{\text {th }}$ alternatives to the $j^{\text {th }}$ factor:

$$
\overline{\mathrm{Y}}_{\mathrm{i} j}=\frac{\mathrm{Y}_{i j}}{\sum_{i=1}^{m} Y_{i j}} \quad(1 \leq \mathrm{i} \leq \mathrm{m}, 1 \leq \mathrm{j} \leq \mathrm{n})
$$

Step 3: Calculation of output Entropy $\left(\dot{\varepsilon}_{j}\right)$

The output entropy $\left(\dot{\varepsilon}_{j}\right)$ of the $\mathrm{j}^{\text {th }}$ factor becomes

$$
\varepsilon_{j}=-\frac{1}{\ln m} \sum_{i=1}^{m} \bar{\Upsilon}_{i j} \ln \bar{\Upsilon}_{i j}
$$

Step 4: Computation of the Weight ( $w j)$ :

Weight of $j$ th criterion ( $w j)$ is as follow

$$
\mathbf{w}_{1}=\frac{1-\dot{k}_{j}}{\sum_{j=1}^{n}\left(1-\underline{k}_{j}\right)}
$$

Where, $\sum_{\mathrm{j}=1}^{\mathrm{n}} \mathrm{w}_{\mathrm{j}}=1$ and $\left(1-\dot{\varepsilon}_{\mathrm{j}}\right)$ is called uncertainty

\subsection{The TOPSIS Method}

In TOPSIS (technique for order preference by similarity to an ideal solution) method the basic principle is that chosen alternative should have the shortest distance from the ideal solution and the farthest distance from the negative-ideal solution [15,7]. The steps of TOPSIS model are as follows:

Step 1: Determine the Normalized decision-making matrix.

Find the normalized decision matrix $r_{i j}$. This can be signified as: 


$$
\mathrm{r}_{\mathrm{ij}}=\frac{y_{i j}}{\sqrt{\sum_{i=1}^{m} y_{i j}^{2}}}
$$

Here, $r_{\mathrm{i} j}$ signifies the normalized performance of $A_{i}$ with respect to characteristic $y_{j}$.

Step 2: Determine the Weighted normalized decision-making matrix.

Construct the weighted normalized decision matrix. Multiply each column of the normalized decision matrix by its associated weight. An element of the new matrix is Obtain the weighted normalized decision matrix, $\mathrm{V}=\left[v_{\mathrm{ij}}\right]$ can be found as;

$$
V=w_{j} x_{\mathrm{i} j}
$$

Here, $\quad \sum_{j=1}^{n} w_{j}=1$

Where, wj demotes the relative weight of the jth criteria or criterion.

Step 3: Determine Ideal and negative-ideal solutions.

Calculate the ideal (best) and negative ideal (worst) solutions in this step. The ideal and negative ideal solution can be expressed as:

The positive ideal solution:

$$
\begin{aligned}
\mathrm{A}^{+} & =\left\{\left(\operatorname{Max}_{\mathrm{i}} V_{\mathrm{i} j} \mid j \in J\right),\left(\operatorname{Min}_{\mathrm{i}} V_{\mathrm{i} j}|j \in J| i=1,2 \ldots m\right)\right\} \\
& =\left\{v_{1}^{+}, v_{2}^{+}, \ldots \ldots v_{j}^{+} \ldots v_{\mathrm{n}}^{+}\right\}
\end{aligned}
$$

The negative ideal solution:

$$
\begin{aligned}
\mathrm{A}^{-} & =\left\{\left(\min _{\mathrm{i}} V_{\mathrm{i} j} \mid j \in J\right),\left(\max _{i} V_{\mathrm{i} j}|j \in J| i=1,2, \ldots, m\right)\right\} \\
& =\left\{v_{1}^{-}, v_{2}^{-}, \ldots v_{j}^{-}, \ldots v_{\mathrm{n}}^{-}\right\}
\end{aligned}
$$

Here, $J=\{j=1,2 \ldots . n \mid j\}:$ Associated with the beneficial attributes.

$J=\{j=1,2 \ldots n \mid j\}:$ Associated with non-beneficial adverse attributes.

Step 4: Determine Computed distance measures.

Define the distance measures. The parting of every another from the ideal result is specified by n-dimensional Euclidean distance from the resulting equations:

$$
\begin{aligned}
& S_{i}^{+}=\sqrt{\sum_{j=1}^{n}\left(v_{i}^{+}-v_{i j}\right)^{2}}, i=1,2, \ldots m . \\
& S_{i}^{-}=\sqrt{\sum_{j=1}^{n}\left(v_{j}^{-}-v_{i j}\right)^{2}}, i=1,2, \ldots m .
\end{aligned}
$$

Step 5: Determine the relative closeness coefficient to the ideal explanation.

$$
\mathrm{C}^{+}=\frac{s_{\mathrm{i}}}{s_{\mathrm{i}}^{+}+s_{\mathrm{i}}^{-}}, i=1,2, \ldots m ; 0 \leq C_{\mathrm{i}}^{+} \leq 1
$$

Step 6: Rank the alternatives.

After the relative closeness coefficient of each alternative is determined, alternatives are ranked according to descending order of $\mathrm{C}^{+}$.

\section{Simple Additive Weighting (SAW)}

Two simple multi-criteria decision-making method are the weighted Sum method and the weighted product method. In the weighted sum method the score of an alternative is equal to the weighted Sum of its evaluation ratings, where the weights are the importance weights associated with each attribute. In the weighted Product method, instead of 
calculating sub-scores by multiplying performance scores times attribute importance. Performance scores are raised to the power of the attribute importance weight.

\subsection{Weighted Sum Method}

The weighted sum method is a straight forward method, especially used in single dimensional problems [16]. If there are $m$ alternatives and $n$ criteria. Then the best alternative is the one that satisfies the following expression:

$$
\boldsymbol{B}^{*}{ }_{w s m}=\operatorname{Max} \sum_{\mathrm{i}}^{j} r_{\mathrm{i} j} w j
$$

For $\mathrm{i}=1,2 \ldots \ldots \ldots \mathrm{m}$ where $\mathrm{B}^{*}{ }_{\text {wsm }}$ is the weighted sum method score of the best alternatives,$n$ is the number of decision criteria. $r_{i j}$ is the actual value of the $i^{\text {th }}$ alternative in terms of the $\mathrm{j}^{\text {th }}$ criterion and $\mathrm{w}_{\mathrm{j}}$ is the weight of importance of the $\mathrm{j}^{\text {th }}$ criterion. The total value of each alternative is equal to the sum of products the difficulties with this method is that it merges when it is applied to multi -dimensional decision making problems. In combining different dimensions, and consequently different units, the additive utility assumption is violated.

\subsection{Weight Product Method (WPM)}

The weighted product method is similar to the weighted sum method. The main difference is that instead of addition in this model there is multiplication. The overall performance score $\left(\mathrm{R}_{\mathrm{i}}\right)$ for the $\mathrm{i}^{\text {th }}$ alternative is computed as [4]:

$$
\boldsymbol{R}_{i}=\prod_{j=1}^{n}\left|\boldsymbol{r}_{i j}\right|^{\mathrm{wj}}
$$

Here, the normalized value of the $\mathrm{i}^{\text {th }}$ alternative on the $\mathrm{j}^{\text {th }}$ criterion is raised to the power of the relative weight of the corresponding criterion. The best alternative is the one having the highest $\mathrm{R}_{\mathrm{i}}$ value.

\section{Result and Discussion}

Table 1 shows factor levels (criteria) for all nine alternatives (Experimental trail). These data are obtained from the process of measuring at Electric discharge machine [17]. These criteria's affect the process parameters. Criteria $(\mathrm{C} 1, \mathrm{C} 2$, and $\mathrm{C} 3)$ are independent variables which are used as input values for MCDM model to determine score and finally show the optimal setting. The decision matrix of MCDM methods determined by the equation (1) and show in Table 1.

Table 1. Experimental Result

\begin{tabular}{cccc}
\hline Trail No. & \multicolumn{3}{c}{ Criteria } \\
\cline { 2 - 4 } Alternatives $)$ & MRR $(C 1)$ & TWR $(C 2)$ & SR $(C 3)$ \\
\hline A-1 & 2.93 & 0.62 & 3.82 \\
\hline $\mathbf{A}-2$ & 6.30 & 1.14 & 10.98 \\
\hline $\mathbf{A}-3$ & 9.74 & 1.97 & 5.48 \\
\hline $\mathbf{A}-4$ & 17.20 & 1.70 & 2.42 \\
\hline $\mathbf{A}-5$ & 28.07 & 2.48 & 8.54 \\
\hline $\mathbf{A - 6}$ & 18.46 & 1.58 & 7.24 \\
\hline $\mathbf{A}-7$ & 30.63 & 2.98 & 3.98 \\
\hline $\mathbf{A - 8}$ & 22.23 & 2.16 & 12.21 \\
\hline $\mathbf{A - 9}$ & 27.51 & 2.67 & 10.49 \\
\hline
\end{tabular}


Three different random weight sets are obtain by entropy method to determining MCDM score. These Weights of the criteria were assigned entropy method have been computed using (Eq.4) and furnished in Table 2.

Table 2. Computation of the Weight for Entropy Method

\begin{tabular}{cccc}
\hline Criteria & \multicolumn{3}{c}{ Computation of the Weight } \\
\cline { 2 - 4 } & MRR & TWR & SR \\
\hline Wj & 0.459 & 0.218 & 0.323 \\
\hline
\end{tabular}

MADM (TOPSIS, WSM, and WPM) has been employed from this step for converting the multiple objective functions into single objective function. Normalized values of quality loss estimates have been computed using Eq. 5 and shown in Table 3.

Table 3. Normalized Values Corresponding to Criteria Values

\begin{tabular}{cccc}
\hline Experiment No. & MRR & TWR & SR \\
\hline $\mathbf{1}$ & 0.047 & 0.101 & 0.159 \\
\hline $\mathbf{2}$ & 0.102 & 0.185 & 0.459 \\
\hline $\mathbf{3}$ & 0.158 & 0.320 & 0.229 \\
\hline $\mathbf{4}$ & 0.280 & 0.276 & 0.101 \\
\hline $\mathbf{5}$ & 0.457 & 0.403 & 0.357 \\
\hline $\mathbf{6}$ & 0.301 & 0.257 & 0.302 \\
\hline $\mathbf{7}$ & 0.499 & 0.484 & 0.166 \\
\hline $\mathbf{8}$ & 0.362 & 0.351 & 0.510 \\
\hline $\mathbf{9}$ & 0.448 & 0.434 & 0.438 \\
\hline
\end{tabular}

Table 4. Weighted Normalized Decision-Making Matrix

\begin{tabular}{cccc}
\hline Exp. No & MRR $(\mathbf{W} 1=\mathbf{0 . 4 5 9})$ & & SR(W3=0.323) \\
\hline Ideal Sequence & $\mathbf{1}$ & $\mathbf{1}$ & $\mathbf{1}$ \\
\hline $\mathbf{1}$ & 0.0219 & 0.0219 & 0.0516 \\
\hline $\mathbf{2}$ & 0.0471 & 0.0404 & 0.1483 \\
\hline $\mathbf{3}$ & 0.0729 & 0.0698 & 0.0740 \\
\hline $\mathbf{4}$ & 0.1288 & 0.0602 & 0.0327 \\
\hline $\mathbf{5}$ & 0.2102 & 0.0879 & 0.1154 \\
\hline $\mathbf{6}$ & 0.1382 & 0.0560 & 0.0978 \\
\hline $\mathbf{7}$ & 0.2293 & 0.1056 & 0.0537 \\
\hline $\mathbf{8}$ & 0.1664 & 0.0766 & 0.1649 \\
\hline $\mathbf{9}$ & 0.2060 & 0.0947 & 0.1417 \\
\hline
\end{tabular}

Weighted normalized matrix has been developed utilizing (Eq.6).For this present work all the factors are given weightage, so weightage given to each parameter is equal to $\mathrm{W} 1=0.459, \mathrm{~W} 2=0.218, \mathrm{~W} 3=0.323$. Table 4 represents the values of weighted normalized matrix.

Table 5. Positive Ideal and Negative-Ideal Solutions

\begin{tabular}{cccc}
\hline Positive & MRR & TWR & SR \\
\cline { 2 - 4 } Ideal & 0.2293 & 0.0219 & 0.0327 \\
\hline $\begin{array}{c}\text { Negative } \\
\text { Ideal }\end{array}$ & 0.0219 & 0.1059 & 0.1649 \\
\hline
\end{tabular}


Positive ideal and negative ideal solution for each attribute have been developed utilizing (Eq. 7-8) and is shown in Table 5.

Table 6. Computed Distance Measures

\begin{tabular}{ccc}
\hline Exp. No & $\mathbf{S}^{+}$ & $\mathbf{S}^{-}$ \\
\hline Ideal Sequence & $\mathbf{1}$ & $\mathbf{1}$ \\
\hline $\mathbf{1}$ & 0.2077 & 0.0198 \\
\hline $\mathbf{2}$ & 0.1959 & 0.0297 \\
\hline $\mathbf{3}$ & 0.1604 & 0.0605 \\
\hline $\mathbf{5}$ & 0.1019 & 0.1264 \\
\hline $\mathbf{6}$ & 0.0302 & 0.1910 \\
\hline $\mathbf{7}$ & 0.0965 & 0.1232 \\
\hline $\mathbf{8}$ & 0.0074 & 0.2197 \\
\hline $\mathbf{9}$ & 0.0833 & 0.1453 \\
\hline
\end{tabular}

The separation measures of each alternative from the ideal solutions have been computed using (Eq.9-10) and furnished in Table 6.

Table 7. Closeness Coefficient

\begin{tabular}{|c|c|c|c|}
\hline Exp. No & $\mathbf{C}^{+}$ & S/N Ratio & Rank \\
\hline Ideal Sequence & & & \\
\hline 1 & 0.0870 & -21.209 & 9 \\
\hline 2 & 0.1316 & -17.614 & 8 \\
\hline 3 & 0.2738 & -11.251 & 7 \\
\hline 4 & 0.5536 & -5.136 & 6 \\
\hline 5 & 0.8634 & -1.275 & 2 \\
\hline 6 & 0.5607 & -5.025 & 5 \\
\hline 7 & 0.9674 & -0.287 & 1 \\
\hline 8 & 0.6356 & -3.936 & 4 \\
\hline 9 & 0.8205 & -1.718 & 3 \\
\hline
\end{tabular}

The closeness coefficients have been computed utilizing Eq. 11 and further it has been treated as Overall Performance Index (OPI) for employment of Taguchi method. S/N ratio values corresponding to each OPI values have been computed to Higher-is-Better (HB) criteria and furnished in Table7. And give rank the preference characteristics order. The alternate with the major relative closeness is the greatest optimal choice.

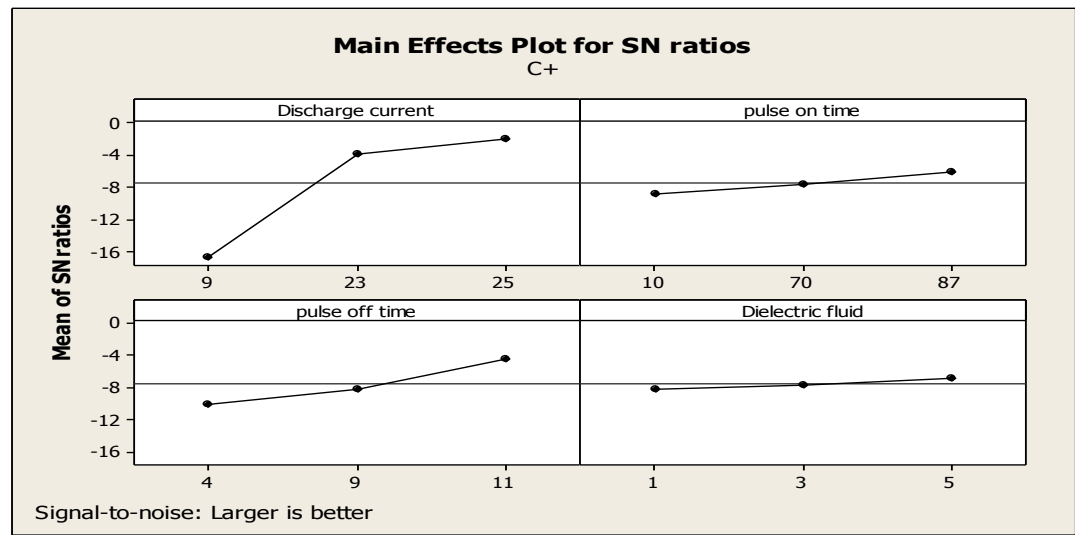

Figure 2. (TOPSIS Method) S/N Ratio Plot for Optimal Setting of Process Parameters 
By using TOPSIS, WSM, WPM approach the optimal setting of parameters is obtained from mean effect plot of $\mathrm{S} / \mathrm{N}$ ratio using MINITAB-16 software as shown in Figure 2-3-4.

The main effects of the variables are displayed on a "main effect" plot, which is given in Figure 2-3-4. Here $\mathrm{X}$ axis is the levels and the response in on $\mathrm{Y}$ axis. A variable which has a strong effect on response will have relatively large main effect and shown on the graph as steep incline slope. Variable which have little effect on response shows as nearly horizontal lines.

Table 8. Response Table for Signal to Noise Ratios for Closeness Coefficient

\begin{tabular}{ccccc}
\hline Input & \multicolumn{3}{c}{ Average closeness coefficient } & \multirow{2}{*}{ Max-Min } \\
\cline { 2 - 4 } parameter & Level 1 & Level 2 & Level 3 & \\
\hline $\begin{array}{c}\text { Discharge } \\
\text { current }\end{array}$ & -16.692 & -3.812 & $\mathbf{- 1 . 9 8 1}$ & 14.711 \\
\hline $\begin{array}{c}\text { Pulse on } \\
\text { time }\end{array}$ & -8.878 & -7.609 & $\mathbf{- 5 . 9 9 8}$ & 2.879 \\
\hline Pulse off time & -10.057 & -8.156 & $\mathbf{- 4 . 2 7 2}$ & 5.785 \\
\hline Dielectric fluid & -8.068 & -7.643 & $\mathbf{- 6 . 7 7 5}$ & 1.293 \\
\hline
\end{tabular}

The closeness coefficient values for each level of process parameters are shown in Table 8. Regardless the category of performance characteristics, a greater closeness coefficient value corresponds to better performance. Therefore, the optimal level of the machining parameters is the level with the greatest closeness coefficient value. Based on the closeness coefficient values given in Table 8, the optimal machining performance for the EDM is obtained for 25A Discharge Current (level 3), $87 \mu$ s Pulse on Time (level 3), $11 \mu$ s Pulse off Time (level 3) and 5g/l Dielectric fluid (level 3). As listed in Table 8, the difference between the maximum and the minimum value of the closeness coefficient of the EDM parameters is as follow: 14.711 for Discharge current, 2.879 for Pulse on time, 5.785 for Pulse off time and 1.293 for Dielectric fluid. The most effective factor affecting performance characteristics is determined by comparing these values. This comparison demonstrated the level of significance of the input parameters over the multi-performance characteristics. The most effective controllable factor is the maximum of these values. Here, the maximum value is 14.711 . This value indicated that the discharge current had the strongest effect on the multi-performance characteristics among the input parameters. The order of importance of the controllable factors to the multi-performance characteristics in the EDM process, in sequence can be listed as follows: Discharge current, Pulse off time, Pulse on time Dielectric fluid. The optimal setting of parameters is obtained from mean effect plot of S/N ratio using MINITAB-16 software and shown in Table 8.

Table 9. Ranking Obtained by WSM

\begin{tabular}{cccc}
\hline Exp. No & WSM & S/N Ratio & Rank \\
\hline $\mathbf{1}$ & 0.0955 & -20.399 & 9 \\
\hline $\mathbf{2}$ & 0.2359 & -12.545 & 6 \\
\hline $\mathbf{3}$ & 0.2168 & -13.278 & 8 \\
\hline $\mathbf{4}$ & 0.2218 & -13.080 & 7 \\
\hline $\mathbf{5}$ & 0.4135 & -7.670 & 5 \\
\hline $\mathbf{6}$ & 0.2921 & -10.689 & 4 \\
\hline $\mathbf{7}$ & 0.3888 & -8.205 & 3 \\
\hline $\mathbf{8}$ & 0.4080 & -7.786 & 1 \\
\hline $\mathbf{9}$ & 0.4424 & -7.083 & \\
\hline
\end{tabular}




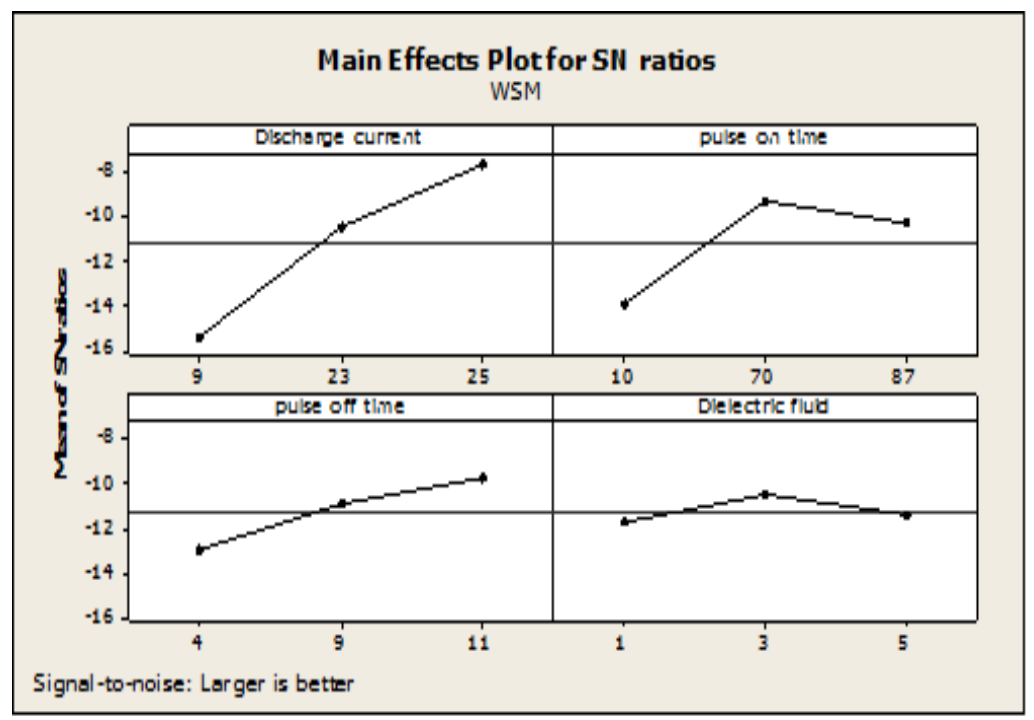

Figure 3. (WSM) S/N Ratio Plot for Optimal Setting of Process Parameters

By using WSM the optimal setting of parameters is obtained from mean effect plot of $\mathrm{S} / \mathrm{N}$ ratio using MINITAB-16 software and shown in Figure 3.

Table 10. Response Table for Signal to Noise Ratios for WSM

\begin{tabular}{ccccc}
\hline \multirow{2}{*}{$\begin{array}{c}\text { Input } \\
\text { parameter }\end{array}$} & \multicolumn{2}{c}{ Response Table for Means (wsm) } & \multirow{2}{*}{ Max-Min } \\
\cline { 2 - 4 } $\begin{array}{c}\text { Discharge } \\
\text { current }\end{array}$ & -15.408 & -10.480 & $\mathbf{- 7 . 6 9 2}$ & 7.716 \\
\hline $\begin{array}{c}\text { Pulse on } \\
\text { time }\end{array}$ & -13.895 & $\mathbf{- 9 . 3 3 4}$ & -10.351 & 4.561 \\
\hline Pulse off time & -12.959 & -10.903 & $\mathbf{- 9 . 7 1 8}$ & 3.240 \\
\hline Dielectric fluid & -11.718 & $\mathbf{- 1 0 . 4 8 0}$ & -11.382 & 1.238 \\
\hline
\end{tabular}

Table 11. Ranking obtained by WPM

\begin{tabular}{cccc}
\hline Exp. No & WPM & S/N Ratio & Rank \\
\hline $\mathbf{1}$ & 0.0830 & -21.618 & 9 \\
\hline $\mathbf{2}$ & 0.1895 & -14.447 & 8 \\
\hline $\mathbf{3}$ & 0.2084 & -13.622 & 6 \\
\hline $\mathbf{4}$ & 0.2012 & -13.927 & 7 \\
\hline $\mathbf{5}$ & 0.4111 & -7.721 & 2 \\
\hline $\mathbf{6}$ & 0.2914 & -10.710 & 5 \\
\hline $\mathbf{7}$ & 0.3480 & -9.168 & 4 \\
\hline $\mathbf{9}$ & 0.4023 & -7.909 & 3 \\
\hline
\end{tabular}

In this section, to show the use of the weighted sum and weighted Product methods, the selection among nine different Experimental trails (alternatives) for Electric discharge machine shown in Table 1, is considered. The alternatives will be evaluated according to the following criteria; MRR, TWR and SR.

By applying Eq. (12) the weighted sum method scores and Eq. (13) the weighted Product method scores of the nine alternatives are calculated. An Experimental trails 9 is considered the best ranked alternative by both the methods, From Table 9 and Table 11 


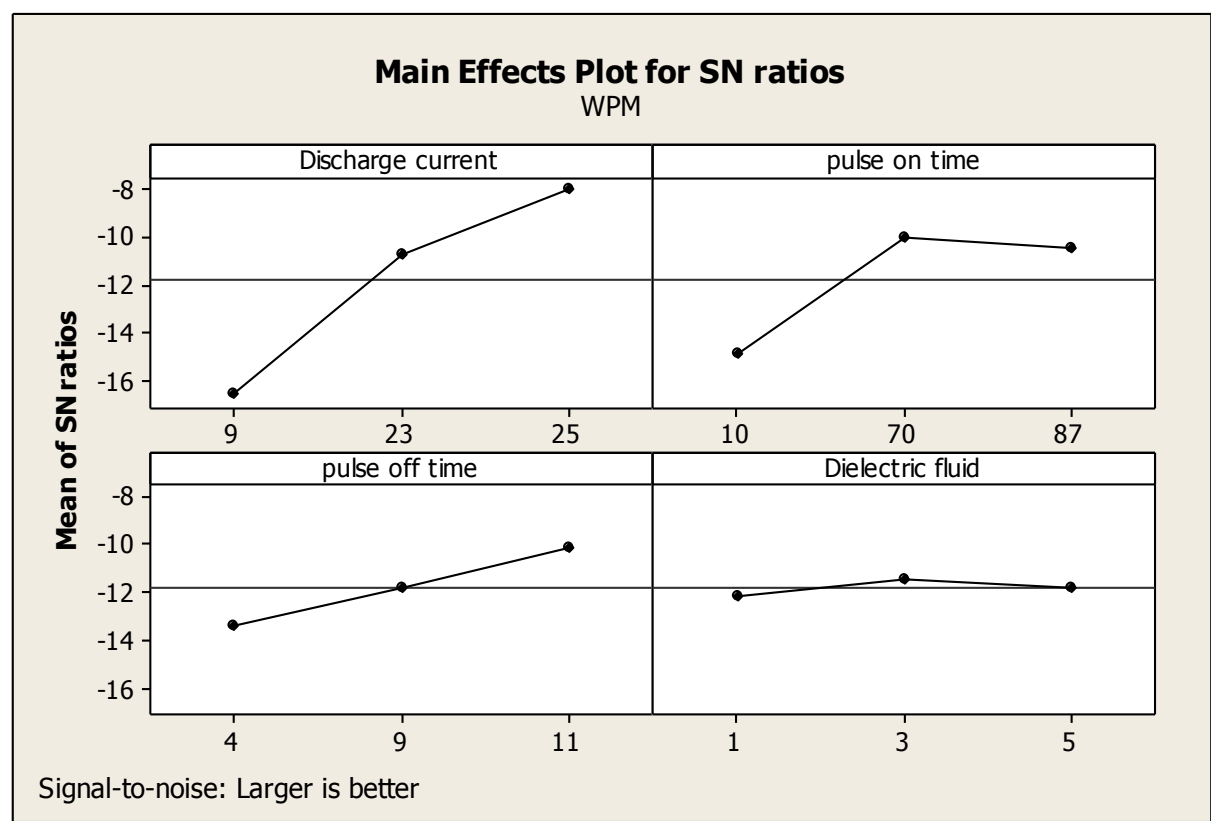

Figure 4. (WPM) S/N Ratio Plot for Optimal Setting of Process Parameters

By using Weight Product method the optimal setting of parameters is obtained from mean effect plot of S/N ratio using MINITAB-16 software and shown in Figure 4.

Table 12. Response Table for Signal to Noise Ratios for WAM

\begin{tabular}{|c|c|c|c|c|}
\hline \multirow{2}{*}{$\begin{array}{c}\text { Input } \\
\text { parameter }\end{array}$} & \multicolumn{3}{|c|}{ Response Table for Means (WAM) } & \multirow{2}{*}{ Max-Mir } \\
\hline & Level1 & Level2 & Level3 & \\
\hline $\begin{array}{c}\text { Discharge } \\
\text { current }\end{array}$ & -16.563 & -10.786 & -8.054 & 8.509 \\
\hline $\begin{array}{l}\text { Pulse on } \\
\text { time }\end{array}$ & -14.905 & -10.026 & -10.472 & 4.879 \\
\hline Pulse off time & -13.413 & -11.820 & -10.171 & 3.242 \\
\hline Dielectric fluid & -12.141 & -11.442 & -11.819 & 0.699 \\
\hline
\end{tabular}

\section{Conclusion}

The present work proposed a Entropy based TOPSIS, Simple Additive Weighting (SAW) methods to solve the multi-response parameter optimization problem in electrical discharge machining. The responses is given ranked based on the scores obtained by the summarization of final global preference.

$>$ In Entropy-TOPSIS approach the optimum factor level combinations is identified based on the closeness coefficient values. The optimal machining performance for the EDM is obtained for 25A Discharge Current (level 3), $87 \mu$ s Pulse on Time (level 3), $11 \mu$ s Pulse off Time (level 3) and $5 \mathrm{~g} / 1$ Dielectric fluid (level 3).

Entropy- Weighted sum method approach the optimum factor level combinations is identified based on the scores. The optimal machining performance for the EDM is obtained for 25A Discharge Current (level 3), $70 \mu$ s Pulse on Time (level 2), $11 \mu$ s Pulse off Time (level 3) and $3 \mathrm{~g} / 1$ Dielectric fluid (level 2).

Entropy- Weight Product Method approach the optimum factor level combinations is identified based on the scores. The optimal machining performance for the EDM is obtained for 25A Discharge Current (level 3), $70 \mu \mathrm{s}$ Pulse on Time (level 2), $11 \mu$ s Pulse off Time (level 3) and $3 \mathrm{~g} / \mathrm{l}$ Dielectric fluid (level 2). 
The computational effort needed to optimize these process parameters. It is illustrated that the methods is efficient and effective for multi-attribute decision making problems in EDM.

\section{Acknowledgements}

The authors express sincere thanks to the anonymous reviewers whose suggestions made the paper a good contributor.

\section{References}

[1] K. H. Ho and S. T. Newman, "State of art electrical discharge machining (EDM)", International Journal of Machine Tools and Manufacturing, vol. 43, no. 13, (2003), pp. 1287-1300.

[2] B. H. Yan, H. C. Tsai and F. Y. Huang, "The effect of EDM of a dielectric of a urea solution in water on modifying the surface of titanium", International journal of Machine Tools and Manufacturing, vol. 45, no. 2, (2005), pp. 194-200.

[3] M. Kiyak and O. Cakir, "Examination of machining parameters on surface roughness in EDM tool steel", Journal of Materials Processing Technology, vol. 191, no. 1-3, (2007), pp. 141-144.

[4] R. V. Rao, "Decision making in the manufacturing environment using graph theory and fuzzy multiple attribute decision making methods", London: Springer-Verlag, (2007).

[5] R. V. Rao, "Decision making in the manufacturing environment using graph theory and fuzzy multiple attribute decision making methods", 2nd ed., London: Springer-Verlag, (2013).

[6] G. Fendel and J. Spronk, "Multiple Criteria Decision Methods and Applications", New York: SpringVerlag, (1983).

[7] C. L. Hwang and K. Yoon, "Multiple Attribute Decision Making Methods and Applications", Springer, Berlin Heidelberg, (1981).

[8] M. Behzadian, S. Khanmohammadi Otaghsara, M. Yazdani and J. Ignatius, "A state-of the-art survey of TOPSIS applications”, Expert Systems with Applications, vol. 39, no. 17, (2012), pp. 13051-13069.

[9] S. H. Zanakis, A. Solomon, N. Wishart and S. Dublish, "Multi-attribute decision making: A simulation comparison of select methods", European journal of operational research, vol. 107, no. 3, (1998), pp. 507-529.

[10] H. Voogd, "Multicriteria Evaluation for Urban and Regional Planning", Pion, London, (1983).

[11] E. Triantaphyllou and S. H. Mann, "An examination of the effectiveness of multi-dimensional decisionmaking methods: A decision-making paradox", Decision Support Systems, vol. 5, (1989), pp. 303-312.

[12] G. K. Bose and S. Mitra, "Study of ECG process while machining Al2O3/Al-IPC using grey- Taguchi methodology", Advances in Production Engineering \& Management, vol. 8, no. 1, (2013), pp. 41-51.

[13] K. L. Wen, T. C. Chang and M. L. You, "The grey entropy and its application in weighting analysis", IEEE International Conference on Systems, Man, and Cybernetics, vol. 2, (1998), pp. 1842-1844.

[14] S. Ding and Z. Shi, "Studies on incident pattern recognition based on information entropy", Journal of Information Science, vol. 31, no. 6, (2005), pp. 497-294.

[15] T.-Y. Chen, "Comparative analysis of SAW and TOPSIS based on interval-valued fuzzy sets: Discussions on score functions and weight constraints", Expert Systems with Applications, vol. 39, (2012), pp. 1848-1861.

[16] E. Triantaphyllou, "Multi-criteria decision making methods: An operation research approach", Encyclopedia of Electrical and Electronic, vol. 15, (1998), pp. 175-186.

[17] D. K. Kasdekar and V. Parashar, "A Study on Responses Parameter of EDM Process in EN-353 Steel Using Grey Relational Analysis", Journal of Mechatronics and Automation, vol. 3, no. 1, (2015), pp. 19 . 
International Journal of Advanced Science and Technology Vol.83 (2015) 